\title{
A granite window to the lower electrical crust and upper mantle
}

\author{
David Beamish \\ British Geological Survey, Keyworth, Nottingham NG12 5GG, UK
}

\begin{abstract}
The structure and properties of the deep crust and upper mantle can be investigated using magnetotelluric observations. Near-surface and upper crustal complexities may distort or limit the capability of the data to adequately resolve deep structure. Granite batholiths have been regarded as windows into the lower crust in the context of seismic reflection data although the granite bodies themselves are not usually detected. Magnetotelluric data from SW England are here used to demonstrate that, in addition to imaging the internal structure and base of a granite, the batholith itself provides a suitable environment for the effective estimation of the resistivity structure to lower crustal and upper mantle depths.
\end{abstract}

\section{INTRODUCTION}

The Carnmenellis granite in SW England (Fig. 1) contains a development site for the extraction of Hot Dry Rock geothermal energy (Batchelor, 1984). Magnetotelluric (MT) data were recently acquired to investigate rock/fluid properties down to depths in excess of $6 \mathrm{~km}$ where commercially exploitable temperatures are anticipated (Parker, 1989). The 11 site MT profile, confined to the granite outcrop, is shown in Fig. 1 in relation to other granite outcrops and the ridge of granite (the Cornubian batholith) which extends to mid-crustal depths.

The main application of the data has been in relation to the internal resistivity structure of the granite. The bulk resistivity, as determined by surface soundings, is principally controlled by the nature of the void space (joints, fractures and pores) together with their fluid content. The MT results that can assist in the geotechnical assessments required for reservoir engineering in crystalline rock are described by Beamish (1990). The bandwidth of the data extends from 100 to $0.01 \mathrm{~Hz}$. Since the entire granite is relatively resistive (e.g. 1000-5000 ohm.m) the data are (theoretically) capable of providing information to depths in excess of $100 \mathrm{~km}$. The ability of the data to adequately resolve lower crustal and upper mantle structure is considered here.

MT sounding data along a profile can be conveniently displayed as a pseudo-section with decreasing frequency representing a form of increasing penetration depth. The tensor nature of the data may require either the selection of a 'rotated' sounding curve (e.g. the resistivity/phase curve in a principal horizontal direction) or the reduction of the tensor to a representative scalar and rotationally invariant curve. A common scalar reduction uses the determinant of the MT tensor and is referred to as the determinant average. As discussed below, one of the main influences on the data is the occurrence of near-surface static distortion. A characteristic of such distortion is that, although it generates parallel offsets in the measured apparent resistivity curves, it does not operate on the phase of the MT response (Larsen, 1977). A phase pseudo-section formed from a reduced (scalar) sounding curve will often provide a semi-quantitative and undistorted image of the resistivity structure encountered (Ranganayaki, 1984). The phase

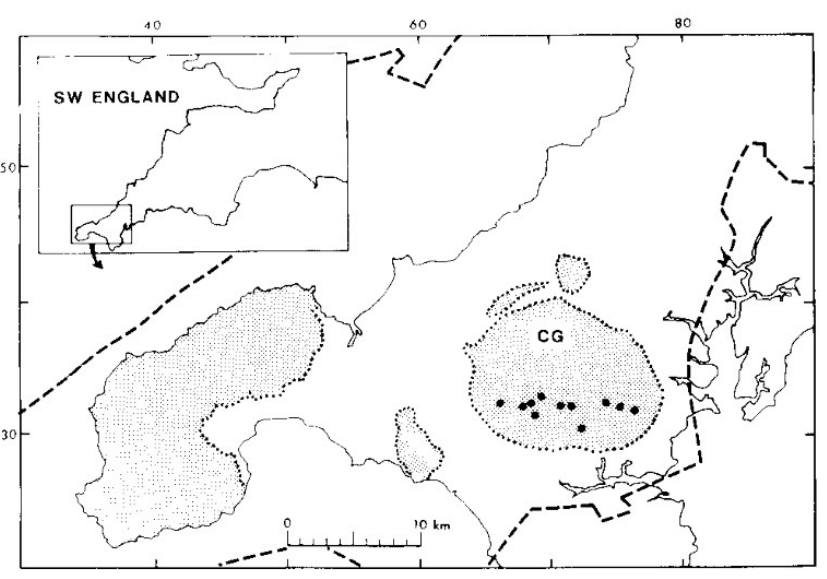

Fig. 1. Site location map. Granite outcrops are shated and the 11 sounding sites are the solid dots on the Carmmenellis srante (CG). Dashed line is the modelled o km depth contour of the root Cormubian batholith (data supplied by the Camborne School of Mines Geothermal Energy Provect). 

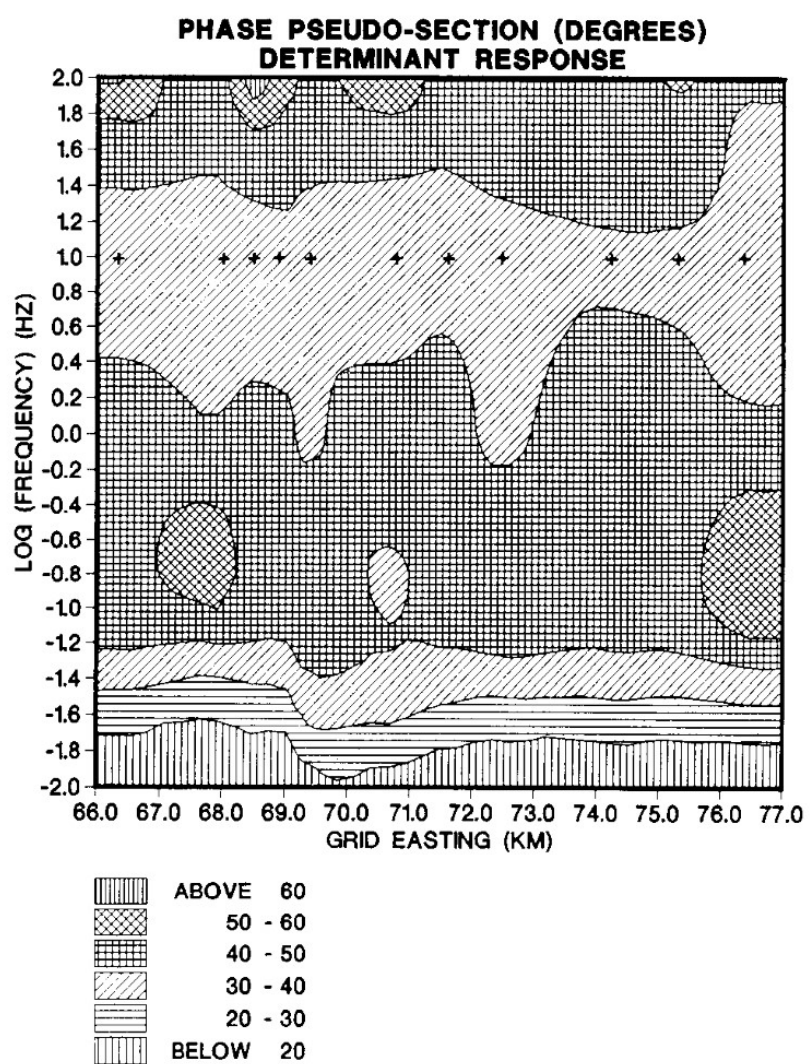

Fig. 2. Phase of the determinant average sounding data displayed as an $E-$ $W$ pseudo-section. Phase is contoured using a linear scale in degrees, interval 10 degrees. The 11 sounding locations, all on the granite outcrop, are indicated by the horizontal sequence of crosses.

pseudo-section obtained from the determinant average response of the 11 soundings across the E-W profile is shown in Fig. 2. The predominantly horizontal zoning indicates the horizontal continuity of the structure encountered across the outcrop of the granite. The approximate penetration depths with decreasing frequency are $5 \mathrm{~km}$ (at $10 \mathrm{~Hz}), 18.5 \mathrm{~km}($ at $1 \mathrm{~Hz}), 50 \mathrm{~km}($ at $0.1 \mathrm{~Hz}$ ) and $200 \mathrm{~km}$ (at $0.01 \mathrm{~Hz}$ ). When allowance is made for data errors (of the order of several degrees) it is clear that the phase data are consistent with a high degree of lateral continuity throughout the whole lithosphere.

\section{A GRANITE-AVERAGE SOUNDING}

A detailed assessment of the sounding data (Beamish, 1990) has revealed that they are influenced by both nearsurface static distortion and by the geometrical form of the batholith. The influences of near-surface distortion are receiving much attention in the literature (Jones, 1988; Sternberg et al., 1988). Many attempts to treat conventional MT data sets containing static distortion effects involve some form of spatial averaging with inevitable loss of spatial resolution. Such procedures are inherently difficult when the geological structure is complex and lateral resistivity gradients exist. A granite batholith, however, can be viewed as a single lithological unit in the same sense that it would normally be modelled using gravity data as possessing a single density contrast (i.e. a simplifying assumption). The results of Fig. 2 suggest that such an assumption is realistic in terms of its lateral, but not its vertical, resistivity structure. The most appropriate treatment for static distortion in the present data set has been to form a 'granite-average' impedance tensor at each sounding frequency using all the soundings on the granite. This approach sacrifices all lateral resolution but attempts to establish the most appropriate sounding curve for assessments of vertical structure. Due to the lateral continuity supplied by the batholith, the simple averaging procedure preserves the frequency characteristics of the tensor sounding curves as shown in Fig. 3. In Fig. 3, 11 sounding curves, derived from the impedance elements $Z x y$, across the granite outcrop (a distance of about $11 \mathrm{~km}$ ) are shown together with the granite-average curve (discrete symbols). The parallel offsets in apparent resistivity across the granite, assumed to be caused by static distortion, are minimized by the formation of the granite-average. The 'undistorted' nature of the phase data across the granite can again be noted. A similar situation holds in relation to the orthogonal $(Z y x)$ sounding data. In addition to the suppression of static distortion it seems evident that the formation of a granite-average sounding will also reduce measurement noise (when present) inherent in both the apparent resistivity and phase data.

\section{D MODELLING}

The situation with regard to the formation of spatial averages across a granite can be further understood by reference to the E-W 2D geoelectric model shown in Fig. 4. The geometrical form of the Carnmenellis granite has been extensively investigated by gravity modelling (Camborne School of Mines Geothermal Energy Project, 1989) and such models can be used as a constraint in the construction of geoelectric sections. The model shown is reasonably realistic and includes the electromagnetically important coastal/seawater interface at a distance of $+14 \mathrm{~km}$ (arrowed and denoted by C). Surface response curves were generated using the finite-element algorithm described by Wannamaker et al. (1987). The H-polarization response (in which lateral effects are most pronounced) computed for this model is also shown at three appropriate frequencies in Fig. 4. Locations entirely within the granite outcrop are indicated by open arrows. The point to note is that all the response perturbations due to lateral resistivity contrasts occur at or outside the margins of the outcrop. The largest perturbation observed across the granite occurs at lower frequencies and is the small gradient observed at 1 and $0.01 \mathrm{~Hz}$. 
GRANITE SOUNDING DATA

NORTH-SOUTH (ZXY) DIRECTION
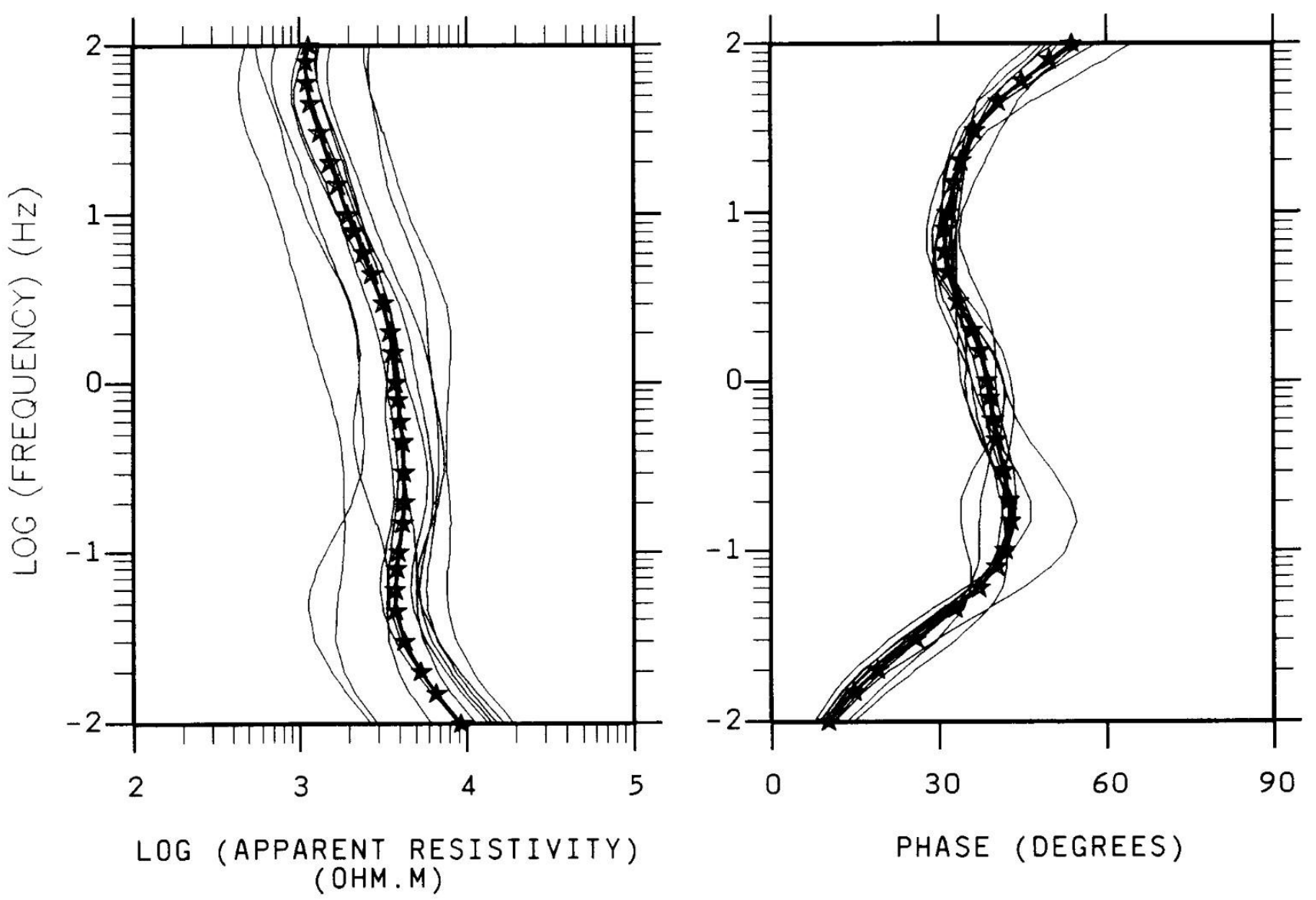

Fig. 3. The 11 measured N-S (i.e. derived from the impedance element Zxy) sounding curves obtained across the granite. The granite-average curve, obtained from these data, is shown by the solid symbols.

Electromagnetically the granite acts as a window in the sense that measurements made across the outcrop are screened from response perturbations due to lateral structural complexity. Although this has only been examined here for 2D models a similar conclusion is likely to apply in the $3 \mathrm{D}$ case. In addition, as discussed above, the lithological continuity provided by the batholith appears to provide a favourable environment for the treatment of near-surface static distortion.

To accommodate assessments of the vertical resistivity structure within and beneath the granite any anisotropy present in the granite-average tensor must be taken into account. The residual anisotropy for the Carnmenellis data was investigated using forward 2-dimensional models of the spatial form of the granite determined from gravity data such as the one shown in Fig. 4. The main conclusion from modelling studies of this type is that the anisotropy in the observed granite-average sounding data can be directly attributed to the 2D influence of the geometrical form of the granite (Beamish, 1990). Further control studies, again using the equivalent 'granite-average' data obtained from $2 \mathrm{D}$ models, have revealed that a rotationally invariant response (again the determinant average but in this case determined from the granite-average data) provides an accurate assessment of the vertical (1D) resistivity structure for this particular problem.

\section{D INVERSION RESULTS}

The results of $1 \mathrm{D}$ inversions of the observed granite-average, determinant response are shown in Fig. 5 for both layered (Fischer and Le Quang, 1981) and smoothly varying (Constable et al., 1987) representations of the vertical resistivity structure. A logarithmic depth scale from 1 to $100 \mathrm{~km}$ is used. The layered (and unconstrained) solution reveals a non-uniform internal structure within the granite 


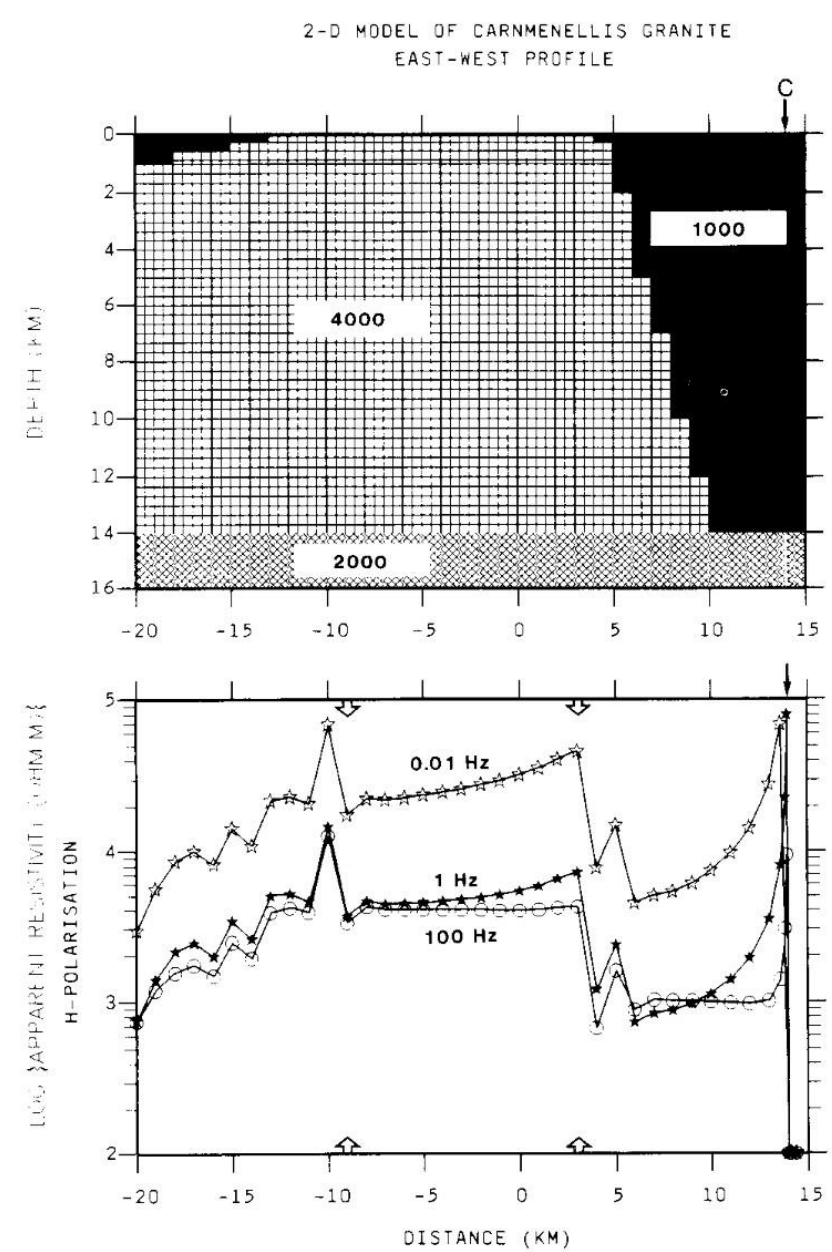

Fig. 4. Upper. Portion of $2 D, E-W$ geoelectric model across the granite outcrop. Resistivities in ohm.m. C is position of coast with maximum depth of seawater being $100 \mathrm{~m}$ to the east of the region shown. Lower. H. polarization model response in apparent resistivity calculated using a finite-element algorithm. Three frequencies of 100,1 and $0.01 \mathrm{~Hz}$. Granite outcrop extends from -10 to $+3 \mathrm{~km}$. Sounding locations entirely within the outcrop are indicated by open arrows.

together with a small resistivity transition (from 'high' to 'low') at a depth of $15.5 \mathrm{~km}$. When allowance is made for the two-dimensionality of the data, the 'true' depth is estimated as $14 \mathrm{~km}$. The correction for $2 \mathrm{D}$ effects is obtained by performing 1D inversions on equivalent data from 2D models (Beamish, 1990). The estimated 'true' depth is very much in accord with the depth to the granite base adopted in regional gravity models (Camborne School of Mines Geothermal Energy Project, 1989). Smooth inverse algorithms are not designed to 'detect' discontinuous behaviour (Constable et al., 1987) so the smooth solution shown in Fig. 5 has an a priori constraint that discontinuous behaviour occurs at the depth of the granite base determined by the layered solution. The detection of such a
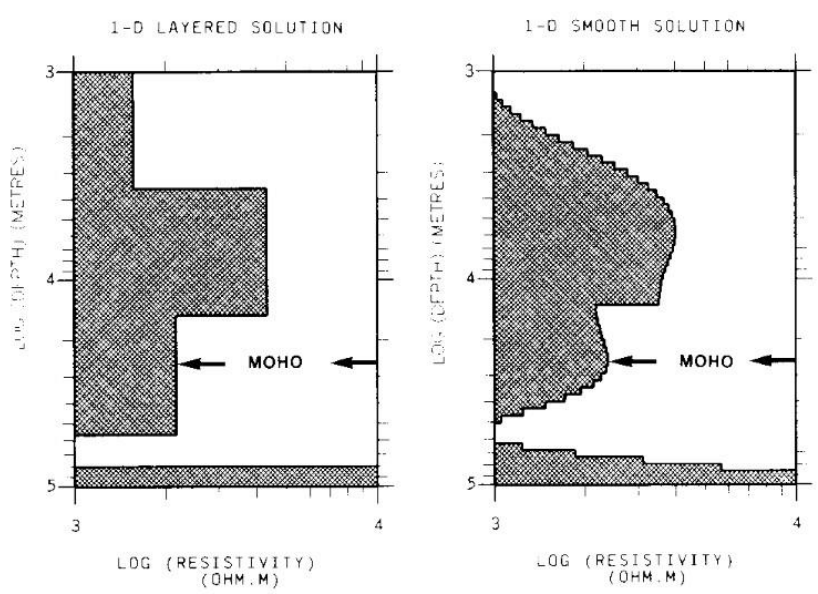

Fig. 5. One-dimensional inversions (layered and smooth) of the graniteaverage, determinant response. Logarithmic (base 10$)$ depth scale. Both solutions achieve an rms error misfit of unity ath respect to the observations. Position of the Moho as determined by seismic refraction data is arrowed.

small resistivity contrast suggests that the spatial averaging of individual tensors has not only minimized static distortion effects but has also minimized measurement noise to produce an increase in the resolution of a deep horizontally-continuous electrical base. It also seems likely that this same principle will operate in relation to those deeper lithospheric features which can also be regarded as horizontally continuous.

\section{THE LOWER CRUST AND UPPER MANTLE}

There is currently much interest in the correlation of deep seismic reflection data (reflectivity) with magnetotelluric results (resistivity) (Beamish and Smythe, 1986; Hyndman and Shearer, 1989). The reflectivity of the offshore crust in the vicinity of the Comubian batholith has been imaged on a number of profiles (the SWAT experiment) in the SW Approaches (BIRPS and ECORS, 1986). SWAT line 6 was designed to pass as close as possible to the exposure of the Cornubian batholith on the Scilly Islands. Although the granite was not imaged, a particularly clear and unusually shallow reflective lower crust was observed (Matthews, 1987) with the Moho forming a reflector base at a depth of about $27 \mathrm{~km}$ (Meissner of al., 1986). Mechanisms which require consideration when correlating reflectivity and resistivity in the lower crust are discussed by Hyndman and Shearer (1989). From the results presented in Fig. 5 it can be noted that the resistivity values obtained for the lower crustal interval beneath the granite lie in the interval 2000 $3000 \mathrm{ohm}$. $\mathrm{m}$ and cannot be considered 'conductive' when advancing a hypothesis for the physical cause of the lower crustal reflectivity. 
Despite the discussion concerning the correlation of low resistivity zones and the reflectivity of the lower crust perhaps a more noteable feature of many lower crustal geoelectric models is the lack of any resistivity expression that can be said to correspond to the seismic Moho. Even in reviews of electrical resistivity in the lower crust (e.g. Haak and Hutton, 1986) there appears very little evidence to support the concept of an 'electrical' Moho; indeed it is not often mentioned. In some cases this may well be due to the difficulties in adequately modelling multi-dimensional data sets but in other cases there appears to be a genuine absence (Jones, 1982). Directly beneath the Carnmenellis granite seismic refraction studies (Brooks et al., 1984) reveal a particularly well-developed Moho with a velocity transition from 6.4 to $8.0 \mathrm{kms}^{-1}$. Raytracing models of the velocity structure (Doody, 1985) provide a Moho depth of $26 \mathrm{~km}$ (arrowed in Fig. 5). The layered solution of Fig. 5 indicates that there is no detectable discontinuity in the resistivity profile at or around the seismic Moho beneath SW England. The smooth solution does however reveal an intriguing change of gradient in the profile centred on a depth of $26-27 \mathrm{~km}$. If such behaviour is genuine it corresponds to a resistivity variation at the extreme limits of detectability.

The resistivity profile through the upper mantle clearly displays a more substantial resistivity variation. It is possible that the lower resistivity zone corresponds to the base of the lithosphere (the lithospheric/asthenospheric transition) currently being mapped (electrically) across mainland Europe (Praus et al., 1990). Although the precise depth and thickness of the less resistive 'layer' is a function of whether the transition is considered abrupt or gradational (Fig. 5), the minimum values of resistivity are found to be in the range $750-850 \mathrm{ohm} . \mathrm{m}$. At present there is a paucity of UK magnetotelluric observations, particularly to the south of the Variscan front, with which the present lithospheric profile may be compared. Although comparisons with crustal resistivity structure and with the electrical depth of the lithosphere observed across the Variscan foreland of Europe are possible, they remain hazardous given the isolation of the single profile discussed here.

\section{CONCLUSIONS}

The main purpose of this study has been to demonstrate the manner in which a granite batholith may act as a window to the lower electrical crust and upper mantle. Electromagnetically the granite acts as a window in the sense that measurements made across the outcrop are screened from response perturbations due to lateral structural complexity. In addition, the lithological continuity, which (from the evidence of gravity studies) should apply in many batholiths, appears to provide a favourable environment for the treatment of static distortion. The formation of a granite-average sounding appears also, for the present data set, to have enhanced signal/noise in relation to the ability of the data to resolve deep horizontally-continuous features.

The results obtained in SW England have been compared with the occurrence of lower crustal reflectivity (imaged offshore) and offer scope for further assessments into the nature and composition of the lower crust. An equally, if not more, important observation is the lack of any resistivity discontinuity that can be said to correspond to the well-developed seismic Moho beneath SW England. Since the Moho represents one of the most important features within the lithosphere further work with regard to its electrical character is recommended. The minimum in the resistivity profile at depths in excess of $50 \mathrm{~km}$ may be taken to represent the lithospheric/asthenospheric transition. If this is correct the relatively shallow lithospheric thickness obtained has a direct counterpart in the Variscides of mainland Europe as mapped both electrically (Praus et al., 1990) and seismologically (Calcagnile and Panza, 1987). Finally it can be noted that Britain is well-endowed with onshore granites which occur within all the major geological terraines and tectonic provinces. It may well be that, due to the current interest in the lower crust arising from the extensive use of deep seismic reflection profiling, such granites may provide useful electrical windows for both lower crustal and whole lithospheric magnetotelluric experiments.

\section{REFERENCES}

Batchelor A.S. (1984) Hot dry rock geothermal exploitation in the United Kingdom, Mod. Geol., 9, 1-41.

Beamish D. (1990) A deep geoelectric survey of a Carnmenellis granite, Geophys. I. Int., 103, in press.

Beamish D. and Smythe D.K. (1986) Geophysical images of the deep crust: the Iapetus suture, J. Geol. Soc. Lond., 143, 489-497.

BIRPS and ECORS (1986) Deep seismic reflection profiling between England, France and Ireland, J. geol. Soc. Lond., 143, 45-52.

Brooks M., Doody J.J. and Al-Rawi F.R.J. (1984) Major crustal reflectors beneath SW England, J. geol. Soc. Lond., 141, 97-103.

Calcagnile G. and Panza G.F. (1987) Properties of the lithosphereasthenosphere system in Europe with a view toward earth conductivity, Pageoph., 125, 241-254.

Camborne School of Mines Geothermal Energy Project (1989) 2C-7 resource evaluation: overview, ETSU Report No. G137-P14A, 71 pp.

Constable S.C., Parker R.L. and Constable C.G. (1987) Occam's inversion: a practical algorithm for generating smooth models from electromagnetic sounding data, Geophysics, 52, 289-300.

Doody J.J. (1985) Deep crustal seismic studies in south west Britain, PhD thesis, University of Wales, 214 pp.

Fischer G. and Le Quang B.V. (1981) Topography and minimisation of the standard deviation in one-dimensional magnetotelluric modelling. Geophys. J. R. astr. Soc., 67, 257-278.

Haak V. and Hutton R. (1986) Electrical resistivity in continental lower crust. In: The Nature of the Lower Continental Crust (ed. by 
J.B. Dawson, D.A. Carswell, J. Hall and K.H. Wedepohl). Spec. Publ. geol. Soc. Lond., 24, 35-49.

Hyndman R.D. and Shearer P.M. (1989) Water in the lower continental crust: modelling magnetotelluric and seismic reflection results, Geophys. J. Int., 98, 343-365.

Jones A.G. (1988) Static shift of magnetotelluric data and its removal in a sedimentary basin environment, Geophysics, 53, 967-978.

Jones A.G. (1982) On the electrical crust-upper mantle in Fennoscandia: no Moho and the Asthenosphere revealed?, Geophys. J. R. astr. Soc., 68, 371-388.

Larsen J.C. (1977) Removal of local surface conductivity effects from low frequency mantle response curves, Acta Geodaet. Geophys. et Montanist., Acad. Sci. Hung., 12, 183-186.

Matthews D.H. (1987) Can we see granites on seismic reflection profiles?, Annales Geophysicae, 5B, 353-356.

Meissner R., Matthews D.H. and Wever T. (1986) The Moho in and around Great Britain, Annales Geophysicae, 4B, 659-664.
Parker R. (1989) The Cambourne School of Mines geothermal energy project, Sci. Drill., 1, 34-41.

Praus O., Pecova J., Petr V., Babuska V. and Plomerova J. (1990) Magnetotelluric and seismological determination of the lithosphere-asthenosphere transition in central Europe, Phys. Earth Planet. Int., 60, 212-228.

Ranganayaki R.P. (1984) An interpretive analysis of magnetotelluric data, Geophysics, 49, 1730-1748.

Sternberg B.K., Washburne J.C. and Pellerin L. (1988) Correction for the static shift in magnetotellurics using transient electromagnetic soundings, Geophysics, 53, 1459-1468.

Wannamaker P.E., Stodt J.A. and Rijo L. (1987) A stable finite element solution for two-dimensional magnetotelluric modelling, Geophys. I. R. astr. Soc., 88, 277-296. 